\title{
1 Vesicular Trafficking Permits Evasion of cGAS/STING Surveillance During Initial Human
}

\section{Papillomavirus Infection}

3

4 Brittany L. Uhlorn ${ }^{1^{*}}$, Robert Jackson ${ }^{2^{*}}$, Shauna M. Bratton ${ }^{3}$, Shuaizhi Li ${ }^{4}$, Koenraad Van

5 Doorslaer ${ }^{1,2,4,5,6, \# \text {, and Samuel K. Campos }}{ }^{1,4,5,7, \#}$

6

$7 \quad{ }^{1}$ Cancer Biology Graduate Interdisciplinary Program, ${ }^{2}$ School of Animal \& Comparative Biomedical

8 Sciences, ${ }^{3}$ Department of Physiology, ${ }^{4}$ Department of Immunobiology, ${ }^{5} \mathrm{BIO}$ Institute, ${ }^{6}$ Genetics

9 Graduate Interdisciplinary Program, ${ }^{7}$ Department of Molecular \& Cellular Biology, The University of

10 Arizona, Tucson, AZ 85721

$\lfloor 1$

*These authors contributed equally

\#Corresponding Authors 


\section{$27 \quad$ Abstract}

28 Oncogenic human papillomaviruses (HPVs) replicate in differentiating epithelium, causing 5\% of

29 cancers worldwide. Like most other DNA viruses, HPV infection initiates after trafficking viral genome

30 (vDNA) to host cell nuclei. Cells possess innate surveillance pathways to detect microbial

31 components or physiological stresses often associated with microbial infections. One of these

32 pathways, cGAS/STING, induces IRF3-dependent antiviral interferon (IFN) responses upon detection

33 of cytosolic DNA. Virion-associated vDNA can activate cGAS/STING during initial viral entry and

34 uncoating/trafficking, and thus cGAS/STING is an obstacle to many DNA viruses. HPV has a unique

35 vesicular trafficking pathway compared to many other DNA viruses. As the capsid uncoats within

36 acidic endosomal compartments, minor capsid protein L2 protrudes across vesicular membranes to

37 facilitate transport of vDNA to the Golgi. L2/vDNA resides within the Golgi lumen until G2/M,

38 whereupon vesicular L2/vDNA traffics along spindle microtubules, tethering to chromosomes to

39 access daughter cell nuclei. L2/vDNA-containing vesicles likely remain intact until G1, following

to nuclear envelope reformation. We hypothesize that this unique vesicular trafficking protects HPV from

H1 cGAS/STING surveillance. Here, we investigate cGAS/STING responses to HPV infection. DNA

12 transfection resulted in acute cGAS/STING activation and downstream IFN responses. In contrast,

t3 HPV infection elicited minimal cGAS/STING and IFN responses. To determine the role of vesicular

14 trafficking in cGAS/STING evasion, we forced premature viral penetration of vesicular membranes

t5 with membrane-perturbing cationic lipids. Such treatment renders a non-infectious trafficking-

t6 defective mutant HPV infectious, yet susceptible to cGAS/STING detection. Overall, HPV evades

17 cGAS/STING by its unique subcellular trafficking, a property that may contribute to establishment of

18 infection.

Importance

¡1 Persistent infection is the main risk factor for all HPV-associated cancers. However, cellular innate ¡2 immune pathways exist to detect and limit viral infections. The cGAS/STING pathway senses 
bioRxiv preprint doi: https://doi.org/10.1101/2020.03.29.014118; this version posted April 2, 2020. The copyright holder for this preprint (which was not certified by peer review) is the author/funder, who has granted bioRxiv a license to display the preprint in perpetuity. It is made available under aCC-BY 4.0 International license.

;3 cytosolic DNA to initiate antiviral IFN responses. Such responses would likely be detrimental towards

;4 the establishment of persistent HPV infections. We therefore hypothesize that HPV evades

;5 cGAS/STING detection via its unique vesicular trafficking mechanism. Here, we show that indeed

j6 HPV is a stealthy virus, capable of infecting keratinocytes with minimal activation of the cGAS/STING

¡7 pathway. Such evasion is dependent on HPV's vesicular trafficking, as perturbation of vesicular ;8 integrity during infection results in sensing of virions. 
Introduction

Human papillomaviruses (HPVs) are circular, double-stranded DNA viruses that infect and replicate in differentiating epithelium. HPV is the most commonly transmitted sexual infection, and oncogenic HPVs cause nearly $5 \%$ of all cancers worldwide and essentially all cervical cancers in

women (1). The HPV lifecycle and viral gene expression is dependent on differentiating epithelium (2-

4). To infect, HPV must traffic its circular dsDNA viral genome (vDNA) to the nucleus of basal

keratinocytes, the only actively dividing cells within differentiating epithelium. Infected basal

keratinocytes maintain vDNA episomes and serve as a reservoir for infected suprabasal cells that support the productive amplification of vDNA and assembly of progeny virions in upper epithelial layers $(5,6)$. Thus, persistently infected basal keratinocytes support sustained production of progeny virions to ensure efficient transmission within hosts. Notably, persistence of high risk HPV types is considered the risk factor for HPV-associated malignancies (7). Unraveling the mechanisms that underlie HPV persistence is therefore important to understand both HPV lifecycle and cancer. Structurally, HPV is a simple virus, yet it has evolved a unique mitosis-dependent mode of subcellular trafficking and delivery of vDNA to the host cell nucleus (8-10). HPV virions bind to the extracellular matrix and cell surface heparan sulfate proteoglycans of basal keratinocytes, where upon proteolysis of the L1 and L2 capsid (11-13) and capsid conformational changes, the virion associates with entry receptor complexes and is endocytosed by the host cell (14-20). As the internalized virion travels through endosomal compartments, most of the L1 capsid is disassembled and degraded en route to the lysosome $(9,21,22)$. In complex with the vDNA, minor capsid protein L2 facilitates retrograde trafficking of the vesicular vDNA away from the degradative endo/lysosomal compartment to the lumen of the Golgi, where it resides during interphase (23-27). L2 is an inducible transmembrane protein that can extend into the cytosol while remaining in complex with luminal vDNA by utilizing a transmembrane-like domain to protrude across local vesicular membranes to physically recruit retromer and other cytosolic sorting factors (8, 28-32). 
bioRxiv preprint doi: https://doi.org/10.1101/2020.03.29.014118; this version posted April 2, 2020. The copyright holder for this preprint (which was not certified by peer review) is the author/funder, who has granted bioRxiv a license to display the preprint in perpetuity. It is made available under aCC-BY 4.0 International license.

Upon entry into mitosis, vesicular L2/vDNA traffics away from the fragmenting Golgi and

accumulates on metaphase chromosomes via a chromatin-binding domain within the central portion of L2 (33). This L2-dependent chromosomal tethering of vDNA-containing vesicles ensures that the vDNA will be partitioned to the daughter cell nuclei after nuclear envelope reassembly and mitotic exit into G1. Our prior work using an L2-BirA fusion virus to report on L2/vDNA compartmentalization within vesicular membranes suggested that L2/vDNA may penetrate the Golgi-derived limiting membranes upon chromosome binding during prometa/metaphase to fully translocate into the nuclear/cytosolic milieu of open mitosis $(27,33)$. However, work from the Sapp and Schiller laboratories suggests that L2/vDNA remains vesicular through the completion of mitosis $(34,35)$. Recent work also shows that some L1 pentamers retrograde traffic along with the L2/vDNA complex towards the nucleus, but their role is unclear $(36,37)$. Additional data suggests that some virions may even remain somewhat intact as partially disassembled capsids during Golgi and post-Golgi nuclear trafficking (34). Within the daughter cell nuclei L2/vDNA somehow escapes the confines of these post-Golgi vesicles and recruits the nuclear ND10/PML body components necessary for efficient early viral gene expression $(34,35,37,38)$.

Several other non-enveloped viruses, such as adenoviruses, nodaviruses, parvoviruses, picornaviruses, and reoviruses, have evolved more direct means of penetrating limiting membrane barriers for vDNA/vRNA delivery and subsequent infection of host cells (39-41). The evolutionary rationale behind the unique mitosis-dependent vesicular trafficking mechanism of HPV is unknown. We and others speculate the trafficking mechanism may impart immunoevasive properties via vDNA shielding behind protective limiting membranes en route to the nucleus $(8,34,42,43)$.

The innate immune system is adept at recognizing microbial nucleic acids as pathogenassociated molecular patterns (PAMPs) through a number of pattern recognition receptors (PRRs) (44). Many PRRs also function to sense nucleic acids of cellular origin as danger-associated molecular patterns (DAMPs). These DAMPs typically consist of mislocalized or modified nucleic acids within the context of physiological stresses or cellular damage often associated with microbial 
10 infections $(45,46)$. In general, the activation of PRRs by nucleic acids leads to NFkB-dependent L1 inflammatory cytokine responses and/or IRF3/7-dependent type-I interferon (IFN) antiviral responses.

cytosolic DNA and downstream IFN responses (47-52). Briefly, cytosolic DNA is recognized by the enzyme cGAS, triggering production of the cyclic dinucleotide 2',3'-cGAMP $(53,54)$. STING, a transmembrane endoplasmic reticulum (ER) protein (55), is activated upon binding to 2',3'-cGAMP (56). Once activated by 2',3'-cGAMP, dimeric STING traffics to a perinuclear Golgi-like compartment $(57,58)$, where it oligomerizes to recruit and activate TBK1 (59-61) to phosphorylate the transcription factor IRF3, stimulating an IFN response (55).

Initial entry, trafficking, and uncoating of many DNA viruses like herpesviruses (HSV-1, KSHV, HCMV), poxviruses (VACV, MVA), asfarviruses (ASFV), and adenoviruses (HAdV serotypes 2, 5, 7, and 35) have been shown to activate cGAS/STING (62-69). Cellular sensing of initial HPV infection has not been formally investigated, but several studies have described roles for the early HPV oncogenes in antagonizing the cGAS/STING/IRF3 axis upon establishment of infection (70-72). Active antagonism of cGAS/STING by the early HPV proteins suggests that cGAS/STING responses would oppose persistent HPV infection. Indeed, IFN responses are detrimental to persistent HPV infections, reducing cellular proliferation and causing apoptosis, episome loss, mutation, and/or integration (73-77). Likewise, it is well known that some HPV early genes - E5, E6, and E7 counteract these detrimental antiviral IFN and IFN-stimulated gene (ISG) responses through a variety of mechanisms (78-81).

Given the ongoing interplay between HPV and antiviral responses, we postulate that evasion of cGAS/STING responses during initial infection would be beneficial to the viral lifecycle. We hypothesize that HPV's unique mitosis-dependent vesicular trafficking serves to enable such evasion. Here, we directly compare human keratinocyte cGAS/STING responses to HPV16 virion infection versus responses to cationic lipid transfection of dsDNA plasmid. We show a striking lack of IRF3 phosphorylation upon HPV16 infection. RNA-seq confirmed the lack of downstream antiviral IFN and 
36 ISG transcriptional responses to HPV16 infection. Perturbance of intracellular vesicular membranes

during infection results in antiviral responses to HPV16 infection, suggesting that HPV's distinctive

vesicular trafficking underlies its stealthy abilities.

\section{Results}

HPV16 Evades cGAS/STING Responses During Initial Infection

We initially investigated cellular cGAS/STING responses to HPV16 pseudovirus in HaCaT

cGAS/STING pathway (83-85). HaCaT cells were either transfected with $250 \mathrm{ng}$ of endotoxin free

dsDNA plasmid ( $p G L 3$ ) for 90 minutes or infected with the HPV16 virion equivalent to 250 ng DNA

(approximately equivalent to 950 ng L1 capsid, encapsidating pGL3). Cellular responses to DNA

and asynchronous (14) with different DNA delivery kinetics compared to transfection, HaCaT cells

were infected with HPV16 pseudovirus and cGAS/STING activity was assessed over an extended 24

hour time course. In these experiments, virus was present until the sample was collected for analysis.

An acute and robust IRF3 phosphorylation (pIRF3) was observed in response to DNA transfection

(Figure 1A, left panel). In contrast, robust phosphorylation of IRF3 was not evident at any time point post-infection with HPV16 pseudovirus, indicating that the cGAS/STING pathway was not able to sense and respond to HPV16 vDNA (Figure 1A, B).

These HPV16 virions package pGL3, which contains a firefly luciferase expression cassette driven by an SV40 promoter. To gauge the relative pGL3 delivery between plasmid transfection and HPV16 infection, luciferase assays were performed 24 hours post-treatment. Since papillomaviruses lack specific genome packaging signals (86), HPV16 pseudoviruses generated in the 293TT system will package both pGL3 reporter plasmid and cellular dsDNA $\leq 8 \mathrm{~kb}$ in size. The majority of virions will contain 293TT-derived DNA, with a smaller fraction containing pGL3 (87). For simplicity, the encapsidated DNA will be referred to as "vDNA" herein, even though it is not the authentic viral 
genome. To account for partial packaging of pGL3, the luciferase numbers for the HPV16 infections were corrected by factoring in the measured virion:pGL3 ratio of 11.16 (See Materials and Methods).

Despite a complete lack of pIRF3 responses, HPV16 infection resulted in equivalent luciferase activity compared to pGL3 transfected cells (Figure 1C), arguing that differences in cellular DNA delivery do not explain the apparent evasion of cGAS/STING surveillance by HPV16.

While immortalized HaCaT cells represent a good model for the basal keratinocytes that HPV has tropism for in vivo, we sought to investigate cGAS/STING responses in cultured primary human foreskin keratinocytes (HFKs), a better model for the cells HPV naturally infects. Primary HFKs were transfected with 500 ng pGL3 or infected with the viral DNA equivalent. pGL3 transfection resulted in robust activation of the cGAS/STING pathway, as seen by the detection of phosphorylated STING (pSTING) and pIRF3 (Figure 2). As before, HPV16 infection did not activate the pathway as detected by phosphorylation of STING or IRF3 during infection (Figure 2A). We observed a delay in activation between HaCaTs (peak near 90 minutes) and HFKs (4 hours). This may be due to differences in transfection efficiency between primary HFKs and HaCaTs, or the kinetics of cellular activation may be slower in primary cells. To ensure comparable delivery of the 500 ng dsDNA via HPV16 virions compared to plasmid transfection we performed a luciferase assay 24 hours post-

transfection/infection. As with HaCaT cells, HPV16 infection again yielded robust luciferase activity as compared to plasmid transfection of HFKs (Figure 2B). These data further support a stealthy mode of HPV infection whereby cGAS/STING responses are avoided.

\section{Transcriptional Responses to DNA Transfection and HPV16 Infection of Primary HFKs}

We performed RNA-seq analysis to profile cellular transcriptional responses to dsDNA delivered via cationic liposomes or HPV16 pseudovirions (Figure 3, Data Set S1, S2). As above, HFKs were either transfected with 500 ng pGL3 or infected with the 500 ng DNA equivalent of HPV16 virions. Total RNA was extracted at the indicated timepoints. At 4 hours post-transfection, 142 genes (95 up and 47 down) were differentially expressed (Figure 3A, Data Set S3) in HFKs relative to mock 
38 water transfection $(n=2, P$-adj $<0.05)$. The up-regulated genes (Figure $3 \mathrm{~B})$, representing expected

transcriptional responses to cytosolic DNA, were functionally enriched (see Data Set S4 for detailed

results) for 82 Gene Ontology (GO) Biological Processes, including "defense response to virus"

(GO:0051607, $P$-adj $=2.26 \times 10^{-15}$ ) as the top hit among innate immune-related terms. Of the 10

enriched Reactome Pathways, the top hit was "Interferon alpha/beta signaling" (REAC:R-HSA-

909733, $P$-adj $=1.16 \times 10^{-7}$ ). In line with our western blot data (Figures 1 and 2), IRF3 was the top

(Figure 3A, Data Set S3) in HFKs $(n=2, P$-adj < 0.05). These up-regulated genes were also

functionally enriched for IFN signaling, with the top five most significantly up-regulated genes (Figure

3B) at 8 hours post-transfection including IFIT2, RSAD2, OASL, IFIT3, and HERC5. The genes with

the highest fold change at 8 hours, ranging from 200 to 500 times above baseline, were CXCL10,

CXCL11, IFNL1, GBP4, and IFIT2. Investigation of the heatmap (Figure 3C) identifies 3 main

functional groups of genes (Figure 3D). Genes that are upregulated acutely, at 4 hours (I;

'Immediate'/'Primary'), and either go back down ('Immediate') or remain up at 8 hours ('Primary'),

genes that are upregulated by 4 hours and continue to increase throughout the experiment (II;

'Intermediate'), and a group of genes that are upregulated by 8 hours but were not significantly

affected at the 4 hour timepoint (III; 'Secondary'). Complete gene sets for each cluster are provided in supplementary Data Set S5.

While 500 ng of pGL3 delivered via cationic liposomes triggered a robust IRF3-based transcriptional response in HFKs, with the strongest overall response at 8 hours post-transfection, the equivalent amount of DNA delivered via HPV16 pseudovirus infection yielded no response (Figure 
14 relative to mock infection with viral storage buffer $(n=3)$. Importantly, preliminary analysis of later

I5 time-points did not show activation of IFN or ISG related transcription (Figure S1). Overall, HPV

L6 infection is unable to induce a classic innate immune response signature in primary HFKs (Figure 3B,

17 D).

Figure 4 highlights the transcriptional response of different IFN and ISGs that were previously demonstrated to interact with the HPV lifecycle (see Discussion). These responses fall into the same

Bypassing HPV's Natural Trafficking Pathway Activates cGAS/STING

cGAS/STING is capable of sensing the incoming vDNA from a number of viruses including adenoviruses, poxviruses, herpesviruses, and the reverse-transcribed cDNA products of lentiviruses like HIV $(62,63,88,89)$. These viruses either breach (non-enveloped viruses) or fuse with (enveloped viruses) intracellular limiting membranes to provide vDNA-capsid complexes access to the cytosol and eventually reach the nucleus. In contrast, HPV uses minor capsid protein L2 to transport vDNA within vesicular membranes en route to the nucleus during mitosis-dependent subcellular trafficking (8-10). We hypothesize this unique vesicular trafficking enables evasion of cellular cGAS/STING surveillance.

To test this hypothesis, we stimulated premature membrane penetration of HPV vDNA to determine if cGAS/STING would then be capable of detecting HPV infection. As no HPV capsid protein mutations are known to cause leakage or transfer of vDNA across vesicular membranes, we instead used cationic lipids which are known to perturb intracellular limiting membranes (90-92). Indeed, our prior work using a sensitive enzyme-based L2 membrane penetration assay showed that 
bioRxiv preprint doi: https://doi.org/10.1101/2020.03.29.014118; this version posted April 2, 2020. The copyright holder for this preprint (which was not certified by peer review) is the author/funder, who has granted bioRxiv a license to display the preprint in perpetuity. It is made available under aCC-BY 4.0 International license.

t0 even low amounts of cationic lipids during HPV infection are capable of disrupting vesicular

membranes that normally limit HPV from cytosolic exposure (27).

HPV16 virions encapsidating pGL3 were mixed to the cationic lipid Lipofectamine 2000, as

described in Materials and Methods. Transmission electron microscopy of this mixture revealed that

intact HPV16 virions were in the close vicinity of submicron cationic lipid complexes (Figure 5A). We

next assessed the ability of wildtype HPV16 and the post-Golgi trafficking defective R302/5A mutant

HPV16 to deliver vDNA to the nucleus in the presence of cationic lipids compared to control media.

cationic lipids caused a modest $\sim 60 \%$ decrease in wildtype HPV16 infectivity, as measured by

luciferase assay for the delivery of virion-packaged pGL3 to the nucleus (Figure 5B). In stark contrast,

cationic lipids rescued the infectivity of R302/5A mutant virus to levels comparable to that of wildtype

HPV16 in the presence of cationic lipids (Figure 5B). The natural subcellular retrograde trafficking of

vDNA is dependent on endosomal acidification, furin cleavage of $L 2$, and $\gamma$-secretase activity. Small

molecule compounds that perturb these processes are potent inhibitors of HPV16 infection (8). The cationic lipid-dependent infectivity of R302/5A was insensitive to endosomal acidification inhibitor BafA, furin inhibitor dRVKR, or $\gamma$-secretase inhibitor XXI (Figure 5C). Collectively these data indicate that cationic lipids mediate vesicular escape of HPV16 to rescue infectivity of R302/5A via an alternative route, independent of the classical HPV16 vesicular trafficking pathway.

Since the use of cationic lipids to bypass the natural subcellular trafficking pathway of HPV rescued infectivity of R302/5A mutant virions, we examined whether premature disruption of vesicular membranes by cationic lipids would allow for activation of the cGAS/STING pathway by HPV16. HaCaT cells were infected with R302/5A virions +/- cationic lipids and cGAS/STING activity was 
assessed by pIRF3 blot as before. Similar to wildtype HPV16 infection (Figure 1), R302/5A mutant infection alone did not activate the cGAS/STING pathway. However, premature vesicle disruption allowed for robust sensing of DNA delivered by R302/5A infection as measured by IRF3 phosphorylation, most prominently at 4 and 8 hours post-infection (Figure 5D, E). Similar results were seen in experiments using wt HPV16 particles (Figure 5F, G). These results indicate that when cationic lipids allow HPV16 virions to breach vesicular compartments, the cGAS/STING pathway is activated, generating a pIRF3 response.

\section{Discussion}

Cells are equipped with numerous PAMP- and DAMP-sensing PRRs, designed to detect the first signs of cellular stress and respond in an IRF3 and NFKB transcription factor-dependent manner

to induce the expression of IFN, antimicrobial ISGs, and proinflammatory cytokine genes (94).

Geared towards recognizing dsDNA in the cytoplasm of a cell, the recently characterized

cGAS/STING pathway has proven to be a critical arm of innate immunity and an important cellular antiviral defense system that is targeted for evasion and/or antagonism by many different viruses ( 51 , $52,95)$.

The HPV early proteins have been shown to block cGAS/STING and downstream IRF3dependent IFN responses, as well as NFKB-dependent cytokine responses through a variety of mechanisms $(70,71,79-81,96,97)$. The early viral proteins that counteract the cellular antiviral responses are not packaged inside within incoming virions. Thus, evasion mechanisms to limit early detection by the innate immune system during early infection would likely benefit later stages of the viral lifecycle. Viral blunting of these cell intrinsic and extrinsic responses promote viral persistence by enabling maintenance of episomal vDNA and reducing inflammatory responses that cause activation of antigen-presenting cells and promote adaptive antiviral immune responses (98). 
bioRxiv preprint doi: https://doi.org/10.1101/2020.03.29.014118; this version posted April 2, 2020. The copyright holder for this preprint (which was not certified by peer review) is the author/funder, who has granted bioRxiv a license to display the preprint in perpetuity. It is made available under aCC-BY 4.0 International license.

Here we investigate cGAS/STING responses to initial HPV16 infection. Although some prior

work has reported minimal induction of IFN and downstream ISGs in response to HPV and canine PV

1 infection $(99,100)$, no studies have directly addressed cGAS/STING responses to incoming HPV16

the pGL3 reporter plasmid does not express any papillomavirus proteins. We find that while

keratinocytes mount acute pIRF3 and downstream IFN/ISG responses to dsDNA plasmid

transfection, dsDNA delivered through HPV16 infection proceeds undetected by cGAS/STING. To

allow for direct comparison, we infected cells with the virion equivalent of $500 \mathrm{ng}$ DNA, corresponding

to a multiplicity of infection (MOI) of 400,000 virions/cell. These super-physiological conditions

strengthen the hypothesis that a physiological infection is unlikely to be detected. The transcriptional

response to dsDNA included type-I IFNB1, type-III IFNL1 and IFNL2, and many IFN-dependent ISGs and chemokines (Figs. 3 and 4). Many of these ISGs, like IFIT1/2/3, ISG15 and CXCL10/11, can be upregulated directly through IRF3-mediated transcription, in addition to secondary IFN-dependent signaling (pSTAT1/pSTAT2/IRF9) mechanisms in certain cellular contexts (101-103).

Not surprisingly, many of these proteins have been implicated in the viral lifecycle. IFIT1 (p56/ISG56) has the potential to directly restrict persistent HPV infection via inhibition of E1dependent episomal vDNA maintenance (77). ISG15 encodes a ubiquitin-like molecule with broad antiviral activity. HERC5 is an E3 ligase that catalyzes the addition of ISG15 to nascent viral proteins leading to the restriction of HPV replication (104). CXCL10, CXCL11, and related CXCL-family chemokines attract activated T cells via CXCR3 $(105,106)$. These chemokine responses may also be detrimental to HPV persistence, as evidenced by a recent mouse papillomavirus study where MmuPV1 was observed to specifically downregulate stress keratin-induced expression of CXCR3 ligands including CXCL10 (107). IFI16 is a DNA-binding inflammasome component and can restrict HPV replication by epigenetically silencing viral gene expression reducing vDNA copy number (108, 109). Several of the genes upregulated by dsDNA transfection are counteracted by papillomavirus gene products. IRF1 and IRF7 gene products augment IFN/ISG responses. IRF1 activity is 
bioRxiv preprint doi: https://doi.org/10.1101/2020.03.29.014118; this version posted April 2, 2020. The copyright holder for this preprint (which was not certified by peer review) is the author/funder, who has granted bioRxiv a license to display the preprint in perpetuity. It is made available under aCC-BY 4.0 International license.

counteracted by the E7 protein from high risk HPVs $(110,111)$. Similarly, RSAD2 (viperin) has broad antiviral activity and is downregulated by cutaneous HPV2 E7 (112).

Double-stranded DNA transfection also induced cell survival and proliferation modulators like ATF3, CDKN2C, and TNFSF10. ATF3 interferes with E6's ability to degrade p53 by preventing E6AP from binding to p53, thus interfering with HPV immortalization (113). Interestingly, ATF3 expression is downregulated in cervical cancer (113). CDKN2C encodes p18INK4C, which restricts cellular proliferation through inhibition of CDK4 and CDK6 (114). Expression of CDKN2C is upregulated by oncogenic E6 proteins (115), suggesting that the virus must be able to replicate in the presence of this anti-proliferative signal. TNFSF10 encodes TRAIL, a member of the TNF family of ligands that can initiate apoptosis (116). The viral E5 protein counteracts TRAIL signaling to block apoptosis and promote HPV infection $(117,118)$. If activated, the induction of cellular effectors would likely restrict initial HPV replication following infection. Thus, initial evasion of cGAS/STING and these downstream cellular IRF3/IFN/ISG responses would likely be beneficial to HPV infection. Collectively, our data suggest that the ability of the viral proteins to antagonize so many of these effectors is not to counteract sensing of the viral DNA upon initial infection. Rather, counteraction of these antiviral/antitumor responses is important for later steps in the viral lifecycle.

Interestingly, HPV16 infection is sensed when vesicular membranes are perturbed by the inclusion of cationic lipids during infection. These findings also indicate that the chromatinized encapsidated vDNA is insufficient to (completely) mask the viral genome from cGAS surveillance, as recent reports have shown that the nucleosomal components of mitotic chromatin prevents efficient cGAS activation by dsDNA $(85,119,120)$. We conclude that HPV's unique L2-dependent vesicular membrane trafficking effectively shields the vDNA PAMP from cytosolic cGAS/STING surveillance during nuclear transit, likely contributing towards viral persistence. A recent report describes a DNAPK mediated DNA-sensing mechanism that appears to be specific to linear DNA (121). Since the HPV genome is circular, it is unlikely that this pathway would be involved in the sensing of HPV infection. 
bioRxiv preprint doi: https://doi.org/10.1101/2020.03.29.014118; this version posted April 2, 2020. The copyright holder for this preprint (which was not certified by peer review) is the author/funder, who has granted bioRxiv a license to display the preprint in perpetuity. It is made available under aCC-BY 4.0 International license.

Our data suggest that papillomaviruses use subcellular trafficking to evade innate immune

detection. Variation in subcellular trafficking routes has been shown to influence innate immune

responses to other viruses. Different trafficking mechanisms during HAdV entry of several cell types

have been shown to affect the stimulation of certain PRRs, influencing distinct immune responses

that are dependent on particular virus- and cell-type combinations (122). For example, different HAdV

serotypes naturally vary in their receptor usage as well as downstream early vs. late endosomal

trafficking pathways. These inherent differences in HAdV serotypes have been shown to affect innate

TLR-dependent sensing of the virus (123). For example, Dynamin-2 (DNM2) is a cellular GTPase

involved in microtubule-dependent transport and scission of endosomes. Modulation of DNM2 affects

the trafficking of $\mathrm{HAdV}$, resulting in an altered cellular cytokine response to infection (124). Reovirus

T1D and T3L strains elicit differing magnitudes of IRF3-dependent IFN responses in a manner dependent on viral uncoating during the late steps of viral entry and trafficking (125). In the case of HIV, the CD4 receptor and the cellular dynein adapter BICD2 play roles in viral trafficking, influencing innate sensing and downstream IFN/ISG responses in infected cells $(126,127)$. Likewise, host phospholipase D affects innate sensing of the influenza A virus by modulation of entry (128). Thus, while differing modes of trafficking can affect cellular responses to many viruses, HPV appears to have evolved an extremely covert means of evading cellular IRF3-dependent responses by hiding incoming vDNA inside the vesicular trafficking network. Other viruses may have evolved similar trafficking-dependent immunoevasion strategies. Adeno-associated viruses (AAVs) are parvoviruses that have recently been shown to retrograde traffic to the Golgi (129). Although cellular pIRF3 responses to initial infection have yet to be investigated, it is tempting to speculate that they too may hide the genome from cytoplasmic DNA sensors. The polyomaviruses (PyVs) are dsDNA viruses that are structurally similar to papillomaviruses. PyVs also undergo subcellular retrograde transport after cellular uptake, but unlike HPVs, SV40 and the related BKPyV and JCPyV bypass the Golgi and traffic directly from endosomes to the ER, where redox-dependent chaperones loosen the VP1 capsid to expose membrane-interacting minor capsid proteins VP2/3 (130-132). The post-ER 
fate of the PyV vDNA is unclear, with data suggesting cell- and virus-type specific differences in transport of vDNA from ER to cytosol/nucleus (133). A recent study found a striking lack of pIRF3 and downstream IFN/ISG responses to BKPyV infection (134), similar to what we observe with papillomaviruses in the present manuscript.

Of note, these smaller viruses do not package tegument or core proteins that may be able to counteract cytoplasmic sensors or their downstream effector proteins. Indeed, these viruses, like papillomaviruses, need to avoid triggering these cytoplasmic sensors. This raises the possibility that multiple viral families may have converged on a trafficking-dependent immunoevasive strategy.

\section{Materials and Methods}

Tissue Culture

HaCaT cells (82) were grown in high glucose DMEM supplemented with $10 \% \mathrm{FBS}$ and Ab/Am. Cells were maintained at $37^{\circ} \mathrm{C}$ with $5 \% \mathrm{CO}_{2}$ and passaged every $2-3$ days. Murine $\mathrm{J} 2$ fibroblasts were grown in high glucose DMEM supplemented with $10 \%$ NCS, $1 \%$ penicillin/streptomycin and $1 \%$ Lglutamine. Cells were maintained at $37^{\circ} \mathrm{C}$ with $5 \% \mathrm{CO} 2$ and passaged every $3-4$ days. To create a feeder layer to support the growth of primary human foreskin keratinocytes, J2 fibroblasts were irradiated every 3-4 days. Cells were removed from continuing culture flasks, resuspended in media in a $15 \mathrm{~mL}$ conical, and irradiated with 6000 rads using a Gammacell 40 cesium- 137 source as described (135). Irradiated cells were plated at 1 million cells per $10 \mathrm{~cm}$ plate to later be used for support of primary keratinocytes. Primary human foreskin keratinocytes (HFKs) were derived from foreskin samples as previously described (136). For continuing culture only, primary HFKs were plated on top of the irradiated $\mathrm{J} 2$ fibroblast layer. After trypsinizing or thawing, primary HFKs were grown in high glucose DMEM and F12 media supplemented with $10 \%$ FBS, $0.4 \mu \mathrm{g} / \mathrm{mL}$

hydrocortisone, $5 \mu \mathrm{g} / \mathrm{mL}$ insulin, $8.4 \mathrm{ng} / \mathrm{mL}$ cholera toxin, $24 \mu \mathrm{g} / \mathrm{mL}$ adenine, and $1 \% \mathrm{~L}$-glutamine. One day after plating, the media was changed to the same as above but with $5 \% \mathrm{FBS}, 10 \mathrm{ng} / \mathrm{mL}$ EGF, and 1\% penicillin/streptomycin. The media was supplemented with $10 \mu \mathrm{M}$ Y-27632 
33 dihydrochloride (Chemdea CD0141) to prevent cellular differentiation and senescence (137). Cells omitted when HFKs were plated for use in experiments.

76

\section{Nucleic Acid Transfections}

HaCaTs were plated at 60,000 cells per well or HFKs were plated at 90,000 cells per well in a 24 -well plate in $500 \mu \mathrm{L}$ complete media. Cells were transfected with 250 or 500 ng endotoxin-free pGL3 using Lipofectamine 2000 (ThermoFisher 11668) in OptiMEM (Life Technologies). Complexes were made in the following manner: $50 \mu \mathrm{L}$ OptiMEM was combined with pGL3 (either 250 or 500 ng) or water, and a separate $50 \mu \mathrm{L}$ of OptiMEM was combined with $2 \mu \mathrm{L}$ Lipofectamine 2000. Each solution was vortexed, combined, vortexed, and incubated for $15 \mathrm{~min}$ at room temperature, prior to dropwise addition of $100 \mu \mathrm{L}$ of complex to the cells. At various timepoints post-transfection, keratinocytes were washed once with PBS and lysed in 1x RIPA lysis buffer $(50 \mathrm{mM}$ Tris- $\mathrm{HCl} \mathrm{pH} 8.0,150 \mathrm{mM} \mathrm{NaCl}, 1 \%$ NP40, 0.5\% sodium deoxycholate, $0.1 \%$ SDS), supplemented with $1 \times$ reducing SDS-PAGE loading buffer, 1x protease inhibitor cocktail (Sigma P1860), 1mM PMSF and 1x PhosSTOP phosphatase inhibitor cocktail (Roche 04906845001). Samples were then boiled for 5 minutes at $95^{\circ} \mathrm{C}$ and stored at $-80^{\circ} \mathrm{C}$ until gel electrophoresis.

\section{HPV16 Production}

The R302/5A mutant was generated by site-directed mutagenesis of pXULL-based constructs using the QuikChange XL-II kit and verified by Sanger sequencing (138). Luciferase expressing wt and R302/5A mutant HPV16 virions were generated as previously described (138). Briefly, 293TT cells were $\mathrm{CaCl}_{2}$ co-transfected with the appropriate pXULL based plasmids and the luciferase reporter plasmid pGL3; virus was then purified by $\mathrm{CsCl}$ gradient. Encapsidated pGL3 content (viral genome equivalent, vge) was determined by SYBR green qPCR against a standard curve dilution series using primers qLuc2-A (ACGATTTTGTGCCAGAGTCC) and qLuc2-B (TATGAGGCAGAGCGACACC), 
19 specific for the luciferase gene in the pGL3 plasmid. DNA concentration of the purified virus was

determined by measurement of OD260 on a nanodrop spectrophotometer. From this, the capsid

21 content was calculated and the capsid:pGL3 ratios were determined. HPVs do not utilize specific

22 vDNA packaging signals, and the 293TT method used to generate PGL3-containing HPV16 virions

23 results in the promiscuous packaging of chromatinized cellular DNA, in addition to chromatinized

24 pGL3 reporter plasmid $(87,139)$. The calculated packaging ratio of 11.16 was therefore used to

normalize luciferase data in experiments comparing pGL3 delivery via cationic lipid transfection to

26 wildtype HPV16 infection (Figure 1 and 2).

HPV16 Infections

29 HaCaTs or HFKs were plated at 60,000 or 90,000 cells per well, respectively, in a 24-well plate in 500

$30 \mu \mathrm{L}$ complete media. Cells were infected the following day with wildtype or R302/5A mutant HPV16

31 virions at $250 \mathrm{ng}$ or $500 \mathrm{ng}$ vDNA equivalents per well for pIRF3 blotting experiments. Infections were

performed at $2 \mathrm{e} 8 \mathrm{vge} /$ well for luciferase experiments. For infection experiments with cationic lipids,

33 HPV16 virions were diluted into $50 \mu \mathrm{L}$ OptiMEM, and a separate $50 \mu \mathrm{L}$ of OptiMEM was combined

34 with $3 \mu \mathrm{L}$ Lipofectamine 2000. Solutions were vortexed, combined, vortexed again and incubated for

3515 min at RT prior to addition of the $100 \mu \mathrm{L}$ onto subconfluent HaCaT or HFK cells plated in $500 \mu \mathrm{L}$ of 36 the appropriate complete media. Nanopure $\mathrm{H}_{2} \mathrm{O}$ was substituted for Lipofectamine 2000 as a control

37 in these experiments. For biochemical inhibition experiments the endosomal acidification and $\mathrm{H}^{+}$-

38 ATPase inhibitor Bafilomycin A (BafA, Millipore 196000) was used at $100 \mathrm{nM}$, furin inhibitor decanoyl-

39 RVKR-cmk (dRVKR, Millipore 344930) was used at $25 \mu \mathrm{M}$, and $\gamma$-secretase inhibitor XXI (XXI,

t0 Millipore 565790) was used at $200 \mathrm{nM}$, as previously described (27). Luciferase assays were

H1 performed $24 \mathrm{hr}$ post-infection.

H3 Luciferase Assay 
14 HPV infected or pGL3 transfected cells were washed once with PBS and lysed in $100 \mu \mathrm{L}$ reporter

lysis buffer (Promega E3971). Luciferase activity was measured on a DTX-800 multimode plate

reader (Beckman Coulter) using Luciferase Assay Reagent (Promega E4550). A fraction of each

lysate was blotted for GAPDH to normalize luciferase activity.

SDS-PAGE \& Western Blotting

Samples were resolved by SDS-PAGE and transferred onto a $0.45 \mu \mathrm{m}$ nitrocellulose membrane.

Rabbit monoclonal anti-GAPDH (Cell Signaling 2118, 1:5000), mouse monoclonal anti-IRF3 (Abcam

50772, 1:100), and rabbit monoclonal anti-STING (Cell Signaling 13647, 1:1000) blots were blocked in $5 \%$ non-fat powdered milk dissolved in Tris-buffered saline containing $0.1 \%$ Tween (TBST). Rabbit monoclonal anti-phospho-IRF3 (Cell Signaling 4947, 1:1000) and rabbit monoclonal anti-phosphoSTING (Cell Signaling 19781, 1:1000) blots were blocked in 100\% Odyssey blocking buffer (Licor 927-40000). Goat anti-rabbit DyLight 680 (Pierce 35568), goat anti-mouse DyLight 680 (Pierce 35518), goat anti-rabbit DyLight 800 (Pierce 535571) and goat anti-mouse DyLight 800 (Pierce 35521) were used as secondary antibodies at 1:10,000 in either 50\% Odyssey blocking buffer/TBST or $5 \%$ milk/TBST. Blots were imaged with the Licor Odyssey Infrared Imaging System. Band intensities were quantified by densitometry using ImageJ v1.52a. Briefly, high resolution images were inverted and bands (both pIRF3 and GAPDH for each blot) were carefully boxed to measure the area and mean intensity of each band. An average background intensity value for each blot was used with the appropriate boxed area to subtract background for each specific band. From these values, pIRF3/GAPDH ratios were calculated for each timepoint/condition. Vehicle/VSB control values for each data series were set to "1.00" and relative pIRF3 values were plotted with Prism software.

\section{RNA-seq Analysis}

RNA was isolated from transfected and infected HFKs using Qiagen's RNeasy Mini Kit (Qiagen 74104). RNA was eluted in $60 \mu \mathrm{L}$ nuclease-free water, further purified with a TURBO DNA-free Kit 
70 (Life Technologies AM1907), then shipped on dry ice to Novogene Corporation (Sacramento, CA).

71 High-quality eukaryotic mRNA libraries were prepared and sequenced on an Illumina platform,

12 yielding >20 million paired-end reads (2x150 bp length) per sample. High-throughput sequencing data

13 were initially processed using the CyVerse Discovery Environment, where FastQC was used for

quality screening, HISAT2 (140) for mapping sequences to the human reference genome GRCh38, and featureCounts (141) for generating gene-level read counts (Data Set S1). Differential expression analysis of read counts, including library-size correction and statistical testing (accounting for batch effects with the DESeq model, as specified in Data Set S2), was performed using the DESeq2 Bioconductor package (142) implemented in R (143) via RStudio's integrated development environment (144). Lists of differentially expressed genes (Data Set S3), with an adjusted $P$-value $<$ 0.05, were analyzed for functional enrichment (Data Set S4) using g:Profiler (145). Heatmaps and volcano plots where constructed in R using the pheatmap (146) and EnhancedVolcano (147) packages. Microsoft Office Suite and Adobe Illustrator software were used to create and compile additional figures.

\section{Transmission Electron Microscopy}

HPV16 samples were prepared with cationic lipids as described above. Each sample was applied to an ultra-thin carbon film over Lacey Carbon Support Film on 400-mesh copper grids (Ted Pella, Inc.) that were glow discharged for 1 min. Excess solution was blotted with Whatman \#1 filter paper and the grid was rapidly stained with $2 \%$ uranyl acetate. The uranyl acetate was immediately blotted with Whatman \#1 filter paper and rapidly stained with $2 \%$ methylamine tungstate. The second stain was immediately blotted away with Whatman \#1 filter paper and allowed to air dry. Data were collected on a JEOL 3200FS microscope operated at $300 \mathrm{kV}$. Images were acquired at a magnification of $87,000 \mathrm{x}$ and 160,000x, and at $1.0 \mu \mathrm{m}$ underfocus using a Gatan UltraScan 4000 charge-coupled device (CCD) camera. 
6 Statistics

77 Statistical analyses were performed using Prism 6 (GraphPad Software). Significant differences were 78 determined by one-way ANOVA followed by Dunnett's or Tukey's multiple comparisons test or two-

9 way ANOVA followed by Sidak's multiple comparisons test. An alpha of 0.05 was used to determine )0 the statistical significance of the null-hypothesis.

\section{Acknowledgments}

3 We thank Anne Cress for the HaCaT cells and Jana Jandova for isolation and initial culturing of the )4 primary HFKs. We thank Tony Day of the UA ARL Imaging Core-Life Sciences North for assistance 55 with TEM. We thank Matthew Bronnimann for generating and purifying wildtype HPV16 virions. We computational infrastructure supported by the National Science Foundation under award numbers

)8 DBI-0735191, DBI-1265383, and DBI-1743442.

\section{$10 \quad$ Funding}

11 S.K.C. is supported by grant 1R01Al108751-01 from the National Institute for Allergy and Infectious

Diseases, grant 1R01GM136853-01 from the National Institute for General Medical Sciences, and by a grant from the Sloan Scholars Mentoring Network of the Social Science Research Council with

14 funds provided by the Alfred P. Sloan Foundation. K.V.D. is supported by State of Arizona Improving I5 Health TRIF funds and by Institutional Research Grant number 128749-IRG-16-124-37-IRG from the

16 American Cancer Society. B.L.U. is a graduate student supported by the National Science 17 Foundation Graduate Research Fellowship Grant DGE-1143953. 


\section{Figure Legends}

\section{Figure 2. HPV16 Evades cGAS/STING Responses in HFKs During Initial Infection}

cGAS/STING responses to pGL3 and wildtype HPV16 in primary HFKs. (A) HFKs were either transfected for 90 min with $500 \mathrm{ng}$ pGL3 or infected for the duration of the experiment with $1900 \mathrm{ng}$ L1 (equivalent to 500 ng DNA) of HPV16 virions. Cells were harvested at various times posttreatment and cGAS/STING responses assessed via western blotting. (A) IRF3 was phosphorylated $4 \mathrm{hr}$ post pGL3 transfection, while IRF3 was not phosphorylated at any time post HPV16 infection with HPV PsV. representative blot of $n=3$ biological replicates. (B) Cells were either transfected for 90 min with 250 ng pGL3 or infected for the duration of the experiment with an equivalent amount of HPV16 virions. Luciferase activity was measured $24 \mathrm{hr}$ post-treatment, normalized to GAPDH, and corrected for pGL3 encapsidation as described in Materials and Methods. ${ }^{*} P<0.05$ by unpaired $t$ test, $n=3$ biological replicates. 
Figure 3. HPV16 Virion Infection Does Not Activate Cellular Responses to dsDNA

17 RNA-seq was used to transcriptionally profile cellular responses to pGL3 DNA introduced via

18 liposome transfection or HPV virion infection. (A) Relative to $\mathrm{H}_{2} \mathrm{O}$ mock-transfection, there were 142

19 significantly $(P$-adj $<0.05)$ differentially expressed genes $(D E G s)$ at $4 \mathrm{hr}$ and 469 DEGs at 8hr post-

;0 transfection, with up-regulated genes functionally enriched for biological processes and pathways

¡1 related to defense responses to virus and IFN signaling. (B) Volcano plots for 4 and 8hr pGL3

;2 transfections $(n=2)$ show significantly DEG genes $(P$-adj $<0.05)$, with up-regulated genes (red)

;3 related to strong innate immune signaling responses. No response was activated 8hr following HPV

j4 virion infection $(n=3)$ relative to viral storage buffer (VSB); inset volcano plot is re-scaled, using

nominal (unadjusted) $P$-values, to show distribution of genes that do not reach significance. (C)

Heatmap of variance-stabilized counts, row-centered, for the top up-regulated cellular response genes $\left(P\right.$-adj $<0.05, \log _{2}$ fold change $>2$, for 4 and 8 hr pGL3-transfection: 164 genes). Genes clustered into three main groups, corresponding to temporal responsiveness post-transfection: cluster I (immediate/primary response at 4hr), cluster II (intermediate response at 4 and increasing at $8 \mathrm{hr}$ ), and cluster III (secondary response at $8 \mathrm{hr}$ ). (D) Metagene $\log _{2}$ fold change values were computed by aggregating response data of all genes within each cluster. Error bars represent 95\% confidence intervals for each gene cluster.

\section{Figure 4. HPV-related DNA-responsive cellular genes are not induced by virion infection}

Normalized RNA-seq count data were plotted for a subset of 15 DNA-responsive cellular genes selected based on prior literature indicating a relationship with HPV. Error bars represent 95\% confidence intervals ( $n=2$ for pGL3 transfection, red, and $n=3$ for HPV virion infection, black).

\section{Figure 5. Bypassing HPV's Natural Trafficking Pathway Activates cGAS/STING}


70 Addition of cationic lipids during infection with translocation-deficient R302/5A mutant HPV16 restores

71 infectivity and allows for cGAS/STING sensing. (A) Electron micrograph of HPV16 complexed with

72 the cationic lipid Lipofectamine 2000. (B) HaCaTs were infected with 2 e8 vge/well of wildtype or

73 R302/5A virion +/- cationic lipid (lipo) for $4 \mathrm{hr}$ and infection was measured by luciferase assay $24 \mathrm{hr}$

74 post-infection. While naturally non-infectious, addition of cationic lipids restored infectivity of the

75 R302/5A mutant to levels nearly comparable to those of wildtype HPV16. Statistics calculated by one-

way ANOVA $(P<0.001)$ followed by Tukey's multiple comparisons test $\left({ }^{\star \star} P<0.01,{ }^{\star \star \star \star} P<0.001\right), n$

$77=3$ biological replicates (C) R302/5A infection in the presence of cationic lipids is insensitive to

78 biochemical inhibitors of endosomal acidification (BafA), furin (dRVKR), and $\gamma$-secretase (XXI).

79 Differences were not significant by one-way ANOVA followed by Dunnett's multiple comparisons test,

$30 n=3$ biological replicates. (D-G) Cells were infected for 4 hr with R302/5A (D, E) or wildtype HPV16

31 (F, G) virion equivalent of 250 ng DNA +/- cationic lipids (lipo) as described in Materials and Methods.

32 Addition of cationic lipids during virus infection resulted in IRF3 phosphorylation at $4 \mathrm{hr}$ and $8 \mathrm{hr}$, while 33 virus infection in media alone did not induce IRF3 phosphorylation, representative blots shown of $n=$

342 biological replicates in both $(\mathbf{D}, \mathbf{F}) .(\mathbf{E}, \mathbf{G})$ Densitometric quantification of western blots. (E) Statistics

were calculated by two-way ANOVA followed by Dunnett's multiple comparisons test. Due to

36 technical aspects of background variability and few replicates, differences did not reach statistical

37 significance $\left(P_{\text {interaction }}=0.331, P=0.125\right.$ at $8 \mathrm{hr}$ time point), $n=2$ biological replicates. (F) Statistics

38 were calculated by two-way ANOVA ( $\left.P_{\text {interaction }}=0.1359\right)$, followed by Dunnett's multiple comparisons

39 test $\left({ }^{*} P<0.05\right), n=2$ biological replicates. 


\section{)2 Supplementary Material}

Figure S1. HPV Virion Infection Does Not Activate Cellular Responses to DNA after 24hr

Aggregate gene responses following pGL3 DNA introduced via liposome transfection (red, $n=2$

Data Set S1. Gene-level read counts, based on the human reference genome GRCh38, for all RNAseq samples $(n=13)$. Tab-delimited, TXT file, $30.8 \mathrm{MB}$ : "evasion_hg_counts.txt", available from https://github.com/KVDlab/Uhlorn-2020-evasion

Data Set S2. RNA-seq sample metadata including batch effects and experimental design groups.

Comma-separated, CSV file, $1 \mathrm{~KB}$ : "evasion_hg_groups.csv", available at

https://github.com/KVDlab/Uhlorn-2020-evasion

Data Set S3. Differentially expressed genes, with gene symbol and description annotations, as well as the full differential gene expression results in additional sheets. XLSX file, 9.7 MB:

"evasion_hg_DEGs.xlsx", available at https://github.com/KVDlab/Uhlorn-2020-evasion

Data Set S4. Functional enrichment analysis of differentially-expressed genes. XLSX file, $0.1 \mathrm{MB}$ : "evasion_hg_functional.xlsx", available at https://github.com/KVDlab/Uhlorn-2020-evasion

Data Set S5. Clusters of cellular genes up-regulated in response to DNA. XLSX file, 0.2 MB: "evasion_hg_clusters.xlsx", available at https://github.com/KVDlab/Uhlorn-2020-evasion 
1. Schiffman M, Castle PE, Jeronimo J, Rodriguez AC, Wacholder S. 2007. Human papillomavirus and cervical cancer. Lancet 370:890-907.

2. Graham SV. 2017. Keratinocyte Differentiation-Dependent Human Papillomavirus Gene Regulation. Viruses 9.

3. Moody C. 2017. Mechanisms by which HPV Induces a Replication Competent Environment in Differentiating Keratinocytes. Viruses 9.

4. Kajitani N, Satsuka A, Kawate A, Sakai H. 2012. Productive Lifecycle of Human Papillomaviruses that Depends Upon Squamous Epithelial Differentiation. Front Microbiol 3:152.

5. Doorbar J, Quint W, Banks L, Bravo IG, Stoler M, Broker TR, Stanley MA. 2012. The biology and life-cycle of human papillomaviruses. Vaccine 30 Suppl 5:F55-70.

6. Schiffman M, Doorbar J, Wentzensen N, de Sanjose S, Fakhry C, Monk BJ, Stanley MA, Franceschi S. 2016. Carcinogenic human papillomavirus infection. Nat Rev Dis Primers 2:16086.

7. Schiffman M, Herrero R, Desalle R, Hildesheim A, Wacholder S, Rodriguez AC, Bratti MC, Sherman ME, Morales J, Guillen D, Alfaro M, Hutchinson M, Wright TC, Solomon D, Chen Z, Schussler J, Castle PE, Burk RD. 2005. The carcinogenicity of human papillomavirus types reflects viral evolution. Virology 337:76-84.

8. Campos SK. 2017. Subcellular Trafficking of the Papillomavirus Genome during Initial Infection: The Remarkable Abilities of Minor Capsid Protein L2. Viruses 9.

9. DiGiuseppe S, Bienkowska-Haba M, Guion LG, Sapp M. 2017. Cruising the cellular highways: How human papillomavirus travels from the surface to the nucleus. Virus Res 231:1-9.

10. Mikulicic S, Florin L. 2019. The endocytic trafficking pathway of oncogenic papillomaviruses. Papillomavirus Res 7:135-137.

11. Bronnimann MP, Calton CM, Chiquette SF, Li S, Lu M, Chapman JA, Bratton KN, Schlegel AM, Campos SK. 2016. Furin Cleavage of L2 During Papillomavirus Infection: Minimal Dependence on Cyclophilins. J Virol doi:10.1128/JVI.00038-16.

12. Cerqueira C, Samperio Ventayol P, Vogeley C, Schelhaas M. 2015. Kallikrein-8 Proteolytically Processes Human Papillomaviruses in the Extracellular Space To Facilitate Entry into Host Cells. J Virol 89:7038-7052.

13. Richards RM, Lowy DR, Schiller JT, Day PM. 2006. Cleavage of the papillomavirus minor capsid protein, L2, at a furin consensus site is necessary for infection. Proc Natl Acad Sci U S A 103:1522-1527.

14. Becker M, Greune L, Schmidt MA, Schelhaas M. 2018. Extracellular conformational changes in the capsid of human papillomaviruses contribute to asynchronous uptake into host cells. J Virol doi:10.1128/JVI.02106-17.

15. Cerqueira C, Liu Y, Kuhling L, Chai W, Hafezi W, van Kuppevelt TH, Kuhn JE, Feizi T, Schelhaas M. 2013. Heparin increases the infectivity of Human Papillomavirus type 16 independent of cell surface proteoglycans and induces L1 epitope exposure. Cell Microbiol 15:1818-1836.

16. Richards KF, Bienkowska-Haba M, Dasgupta J, Chen XS, Sapp M. 2013. Multiple heparan sulfate binding site engagements are required for the infectious entry of human papillomavirus type 16. J Virol 87:11426-11437.

17. Mikulicic S, Finke J, Boukhallouk F, Wustenhagen E, Sons D, Homsi Y, Reiss K, Lang T, Florin L. 2019. ADAM17-dependent signaling is required for oncogenic human papillomavirus entry platform assembly. Elife 8. 
18. Bannach C, Brinkert P, Kuhling L, Greune L, Schmidt MA, Schelhaas M. 2020. Epidermal growth factor receptor and Abl2 kinase regulate distinct steps of Human papillomavirus type 16 endocytosis. J Virol doi:10.1128/JVI.02143-19.

19. Surviladze Z, Dziduszko A, Ozbun MA. 2012. Essential roles for soluble virion-associated heparan sulfonated proteoglycans and growth factors in human papillomavirus infections. PLoS Pathog 8:e1002519.

20. Surviladze Z, Sterk RT, DeHaro SA, Ozbun MA. 2013. Cellular entry of human papillomavirus type 16 involves activation of the phosphatidylinositol 3-kinase/Akt/mTOR pathway and inhibition of autophagy. J Virol 87:2508-2517.

21. Gräßel L, Fast LA, Scheffer KD, Boukhallouk F, Spoden GA, Tenzer S, Boller K, Bago R, Rajesh S, Overduin M, Berditchevski F, Florin L. 2016. The CD63-Syntenin-1 Complex Controls Post-Endocytic Trafficking of Oncogenic Human Papillomaviruses. Sci Rep 6:32337.

22. Schelhaas M, Shah B, Holzer M, Blattmann P, Kuhling L, Day PM, Schiller JT, Helenius A. 2012. Entry of human papillomavirus type 16 by actin-dependent, clathrin- and lipid raftindependent endocytosis. PLoS Pathog 8:e1002657.

23. Day PM, Thompson CD, Schowalter RM, Lowy DR, Schiller JT. 2013. Identification of a role for the trans-Golgi network in human papillomavirus 16 pseudovirus infection. J Virol 87:3862-3870.

24. Lipovsky A, Popa A, Pimienta G, Wyler M, Bhan A, Kuruvilla L, Guie MA, Poffenberger AC, Nelson CD, Atwood WJ, DiMaio D. 2013. Genome-wide siRNA screen identifies the retromer as a cellular entry factor for human papillomavirus. Proc Natl Acad Sci U S A 110:7452-7457.

25. Popa A, Zhang W, Harrison MS, Goodner K, Kazakov T, Goodwin EC, Lipovsky A, Burd CG, DiMaio D. 2015. Direct binding of retromer to human papillomavirus type 16 minor capsid protein L2 mediates endosome exit during viral infection. PLoS Pathog 11:e1004699.

26. Zhang W, Kazakov T, Popa A, DiMaio D. 2014. Vesicular trafficking of incoming human papillomavirus 16 to the Golgi apparatus and endoplasmic reticulum requires gammasecretase activity. MBio 5:e01777-01714.

27. Calton CM, Bronnimann MP, Manson AR, Li S, Chapman JA, Suarez-Berumen M, Williamson TR, Molugu SK, Bernal RA, Campos SK. 2017. Translocation of the papillomavirus L2/vDNA complex across the limiting membrane requires the onset of mitosis. PLoS Pathog 13:e1006200.

28. Bronnimann MP, Chapman JA, Park CK, Campos SK. 2013. A transmembrane domain and GxxxG motifs within L2 are essential for papillomavirus infection. J Virol 87:464-473.

29. DiGiuseppe S, Keiffer TR, Bienkowska-Haba M, Luszczek W, Guion LG, Muller M, Sapp M. 2015. Topography of the Human Papillomavirus Minor Capsid Protein L2 during Vesicular Trafficking of Infectious Entry. J Virol 89:10442-10452.

30. Inoue T, Zhang P, Zhang W, Goodner-Bingham K, Dupzyk A, DiMaio D, Tsai B. 2018. gamma-Secretase promotes membrane insertion of the human papillomavirus $\mathrm{L} 2$ capsid protein during virus infection. J Cell Biol 217:3545-3559.

31. Zhang P, Monteiro da Silva G, Deatherage C, Burd C, DiMaio D. 2018. Cell-Penetrating Peptide Mediates Intracellular Membrane Passage of Human Papillomavirus L2 Protein to Trigger Retrograde Trafficking. Cell 174:1465-1476 e1413.

32. Bergant M, Peternel S, Pim D, Broniarczyk J, Banks L. 2017. Characterizing the spatiotemporal role of sorting nexin 17 in human papillomavirus trafficking. J Gen Virol 98:715-725.

33. Aydin I, Villalonga-Planells R, Greune L, Bronnimann MP, Calton CM, Becker M, Lai KY, Campos SK, Schmidt MA, Schelhaas M. 2017. A central region in the minor capsid protein of papillomaviruses facilitates viral genome tethering and membrane penetration for mitotic nuclear entry. PLoS Pathog 13:e1006308.

34. Day PM, Weisberg AS, Thompson CD, Hughes MM, Pang YY, Lowy DR, Schiller JT. 2019. Human Papillomavirus 16 Capsids Mediate Nuclear Entry during Infection. J Virol 93. 
35. DiGiuseppe S, Luszczek W, Keiffer TR, Bienkowska-Haba M, Guion LG, Sapp MJ. 2016. Incoming human papillomavirus type 16 genome resides in a vesicular compartment throughout mitosis. Proc Natl Acad Sci U S A 113:6289-6294.

36. DiGiuseppe S, Bienkowska-Haba M, Guion LGM, Keiffer TR, Sapp M. 2017. Human Papillomavirus Major Capsid Protein L1 Remains Associated with the Incoming Viral Genome throughout the Entry Process. J Virol 91.

37. Guion L, Bienkowska-Haba M, DiGiuseppe S, Florin L, Sapp M. 2019. PML nuclear bodyresiding proteins sequentially associate with HPV genome after infectious nuclear delivery. PLoS Pathog 15:e1007590.

38. Day PM, Baker CC, Lowy DR, Schiller JT. 2004. Establishment of papillomavirus infection is enhanced by promyelocytic leukemia protein (PML) expression. Proc Natl Acad Sci U S A 101:14252-14257.

39. Kumar CS, Dey D, Ghosh S, Banerjee M. 2018. Breach: Host Membrane Penetration and Entry by Nonenveloped Viruses. Trends Microbiol 26:525-537.

40. Moyer CL, Nemerow GR. 2011. Viral weapons of membrane destruction: variable modes of membrane penetration by non-enveloped viruses. Curr Opin Virol 1:44-49.

41. Tsai B. 2007. Penetration of nonenveloped viruses into the cytoplasm. Annu Rev Cell Dev Biol 23:23-43.

42. DiGiuseppe S, Bienkowska-Haba M, Sapp M. 2016. Human Papillomavirus Entry: Hiding in a Bubble. J Virol 90:8032-8035.

43. Spriggs CC, Harwood MC, Tsai B. 2019. How non-enveloped viruses hijack host machineries to cause infection. Adv Virus Res 104:97-122.

44. Takeuchi O, Akira S. 2010. Pattern recognition receptors and inflammation. Cell 140:805-820.

45. Gong T, Liu L, Jiang W, Zhou R. 2020. DAMP-sensing receptors in sterile inflammation and inflammatory diseases. Nat Rev Immunol 20:95-112.

46. Patel S. 2018. Danger-Associated Molecular Patterns (DAMPs): the Derivatives and Triggers of Inflammation. Curr Allergy Asthma Rep 18:63.

47. Wu J, Chen ZJ. 2014. Innate immune sensing and signaling of cytosolic nucleic acids. Annu Rev Immunol 32:461-488.

48. Li T, Chen ZJ. 2018. The cGAS-cGAMP-STING pathway connects DNA damage to inflammation, senescence, and cancer. J Exp Med 215:1287-1299.

49. Chen Q, Sun L, Chen ZJ. 2016. Regulation and function of the cGAS-STING pathway of cytosolic DNA sensing. Nat Immunol 17:1142-1149.

50. Tao J, Zhou X, Jiang Z. 2016. cGAS-cGAMP-STING: The three musketeers of cytosolic DNA sensing and signaling. IUBMB Life 68:858-870.

51. Ablasser A, Chen ZJ. 2019. cGAS in action: Expanding roles in immunity and inflammation. Science 363.

52. Motwani M, Pesiridis S, Fitzgerald KA. 2019. DNA sensing by the cGAS-STING pathway in health and disease. Nat Rev Genet 20:657-674.

53. Ablasser A, Schmid-Burgk JL, Hemmerling I, Horvath GL, Schmidt T, Latz E, Hornung V. 2013. Cell intrinsic immunity spreads to bystander cells via the intercellular transfer of cGAMP. Nature 503:530-534.

54. Sun L, Wu J, Du F, Chen X, Chen ZJ. 2013. Cyclic GMP-AMP synthase is a cytosolic DNA sensor that activates the type I interferon pathway. Science 339:786-791.

55. Ishikawa H, Barber GN. 2008. STING is an endoplasmic reticulum adaptor that facilitates innate immune signalling. Nature 455:674-678.

56. Yin Q, Tian Y, Kabaleeswaran V, Jiang X, Tu D, Eck MJ, Chen ZJ, Wu H. 2012. Cyclic diGMP sensing via the innate immune signaling protein STING. Mol Cell 46:735-745.

57. Ishikawa H, Ma Z, Barber GN. 2009. STING regulates intracellular DNA-mediated, type I interferon-dependent innate immunity. Nature 461:788-792. 
58. Saitoh T, Fujita N, Hayashi T, Takahara K, Satoh T, Lee H, Matsunaga K, Kageyama S, Omori H, Noda T, Yamamoto N, Kawai T, Ishii K, Takeuchi O, Yoshimori T, Akira S. 2009. Atg9a controls dsDNA-driven dynamic translocation of STING and the innate immune response. Proc Natl Acad Sci U S A 106:20842-20846.

59. Shang G, Zhang C, Chen ZJ, Bai XC, Zhang X. 2019. Cryo-EM structures of STING reveal its mechanism of activation by cyclic GMP-AMP. Nature 567:389-393.

60. Zhang C, Shang G, Gui X, Zhang X, Bai XC, Chen ZJ. 2019. Structural basis of STING binding with and phosphorylation by TBK1. Nature 567:394-398.

61. Tanaka Y, Chen ZJ. 2012. STING specifies IRF3 phosphorylation by TBK1 in the cytosolic DNA signaling pathway. Sci Signal 5:ra20.

62. Reinert LS, Lopusna K, Winther H, Sun C, Thomsen MK, Nandakumar R, Mogensen TH, Meyer M, Vaegter C, Nyengaard JR, Fitzgerald KA, Paludan SR. 2016. Sensing of HSV-1 by the cGAS-STING pathway in microglia orchestrates antiviral defence in the CNS. Nat Commun 7:13348.

63. Lam E, Stein S, Falck-Pedersen E. 2014. Adenovirus detection by the cGAS/STING/TBK1 DNA sensing cascade. J Virol 88:974-981.

64. Xia P, Ye B, Wang S, Zhu X, Du Y, Xiong Z, Tian Y, Fan Z. 2016. Glutamylation of the DNA sensor cGAS regulates its binding and synthase activity in antiviral immunity. Nat Immunol 17:369-378.

65. Dai P, Wang W, Cao H, Avogadri F, Dai L, Drexler I, Joyce JA, Li XD, Chen Z, Merghoub T, Shuman S, Deng L. 2014. Modified vaccinia virus Ankara triggers type I IFN production in murine conventional dendritic cells via a cGAS/STING-mediated cytosolic DNA-sensing pathway. PLoS Pathog 10:e1003989.

66. Ma Z, Jacobs SR, West JA, Stopford C, Zhang Z, Davis Z, Barber GN, Glaunsinger BA, Dittmer DP, Damania B. 2015. Modulation of the cGAS-STING DNA sensing pathway by gammaherpesviruses. Proc Natl Acad Sci U S A 112:E4306-4315.

67. Fu YZ, Su S, Gao YQ, Wang PP, Huang ZF, Hu MM, Luo WW, Li S, Luo MH, Wang YY, Shu HB. 2017. Human Cytomegalovirus Tegument Protein UL82 Inhibits STING-Mediated Signaling to Evade Antiviral Immunity. Cell Host Microbe 21:231-243.

68. Paijo J, Doring M, Spanier J, Grabski E, Nooruzzaman M, Schmidt T, Witte G, Messerle M, Hornung V, Kaever V, Kalinke U. 2016. cGAS Senses Human Cytomegalovirus and Induces Type I Interferon Responses in Human Monocyte-Derived Cells. PLoS Pathog 12:e1005546.

69. Garcia-Belmonte R, Perez-Nunez D, Pittau M, Richt JA, Revilla Y. 2019. African Swine Fever Virus Armenia/07 Virulent Strain Controls Interferon Beta Production through the cGASSTING Pathway. J Virol 93.

70. Lau L, Gray EE, Brunette RL, Stetson DB. 2015. DNA tumor virus oncogenes antagonize the cGAS-STING DNA-sensing pathway. Science 350:568-571.

71. Ronco LV, Karpova AY, Vidal M, Howley PM. 1998. Human papillomavirus 16 E6 oncoprotein binds to interferon regulatory factor-3 and inhibits its transcriptional activity. Genes Dev 12:2061-2072.

72. Shaikh MH, Bortnik V, McMillan NA, Idris A. 2019. cGAS-STING responses are dampened in high-risk HPV type 16 positive head and neck squamous cell carcinoma cells. Microb Pathog 132:162-165.

73. Chang YE, Pena L, Sen GC, Park JK, Laimins LA. 2002. Long-term effect of interferon on keratinocytes that maintain human papillomavirus type 31. J Virol 76:8864-8874.

74. Herdman MT, Pett MR, Roberts I, Alazawi WO, Teschendorff AE, Zhang XY, Stanley MA, Coleman N. 2006. Interferon-beta treatment of cervical keratinocytes naturally infected with human papillomavirus 16 episomes promotes rapid reduction in episome numbers and emergence of latent integrants. Carcinogenesis 27:2341-2353. 
75. Lace MJ, Anson JR, Haugen TH, Dierdorff JM, Turek LP. 2015. Interferon treatment of human keratinocytes harboring extrachromosomal, persistent HPV-16 plasmid genomes induces de novo viral integration. Carcinogenesis 36:151-159.

76. Liu H, Golji J, Brodeur LK, Chung FS, Chen JT, deBeaumont RS, Bullock CP, Jones MD, Kerr G, Li L, Rakiec DP, Schlabach MR, Sovath S, Growney JD, Pagliarini RA, Ruddy DA, Maclsaac KD, Korn JM, McDonald ER, 3rd. 2019. Tumor-derived IFN triggers chronic pathway agonism and sensitivity to ADAR loss. Nat Med 25:95-102.

77. Terenzi F, Saikia P, Sen GC. 2008. Interferon-inducible protein, P56, inhibits HPV DNA replication by binding to the viral protein $\mathrm{E} 1$. EMBO J 27:3311-3321.

78. Ferreira AR, Ramalho AC, Marques M, Ribeiro D. 2020. The Interplay between Antiviral Signalling and Carcinogenesis in Human Papillomavirus Infections. Cancers (Basel) 12.

79. James CD, Fontan CT, Otoa R, Das D, Prabhakar AT, Wang X, Bristol ML, Morgan IM. 2020. Human Papillomavirus 16 E6 and E7 Synergistically Repress Innate Immune Gene Transcription. mSphere 5.

80. Lo Cigno I, Calati F, Borgogna C, Zevini A, Albertini S, Martuscelli L, De Andrea M, Hiscott J, Landolfo S, Gariglio M. 2020. Human Papillomavirus E7 Oncoprotein Subverts Host Innate Immunity via SUV39H1-Mediated Epigenetic Silencing of Immune Sensor Genes. J Virol 94.

81. Scott ML, Woodby BL, Ulicny J, Raikhy G, Orr AW, Songock WK, Bodily JM. 2020. Human Papillomavirus 16 E5 Inhibits Interferon Signaling and Supports Episomal Viral Maintenance. J Virol 94.

82. Boukamp P, Petrussevska RT, Breitkreutz D, Hornung J, Markham A, Fusenig NE. 1988. Normal keratinization in a spontaneously immortalized aneuploid human keratinocyte cell line. J Cell Biol 106:761-771.

83. Kim JA, Park SK, Seo SW, Lee CH, Shin OS. 2017. STING Is Involved in Antiviral Immune Response against VZV Infection via the Induction of Type I and III IFN Pathways. J Invest Dermatol 137:2101-2109.

84. Skouboe MK, Knudsen A, Reinert LS, Boularan C, Lioux T, Perouzel E, Thomsen MK, Paludan SR. 2018. STING agonists enable antiviral cross-talk between human cells and confer protection against genital herpes in mice. PLoS Pathog 14:e1006976.

85. Uhlorn BL, Gamez ER, Campos SK. 2019. Attenuation of cGAS/STING Activity During Mitosis. bioRxiv doi:10.1101/2019.12.19.883090:2019.2012.2019.883090.

86. Cerqueira C, Schiller JT. 2017. Papillomavirus assembly: An overview and perspectives. Virus Res 231:103-107.

87. Buck CB, Pastrana DV, Lowy DR, Schiller JT. 2005. Generation of HPV pseudovirions using transfection and their use in neutralization assays. Methods Mol Med 119:445-462.

88. Gao D, Wu J, Wu YT, Du F, Aroh C, Yan N, Sun L, Chen ZJ. 2013. Cyclic GMP-AMP synthase is an innate immune sensor of HIV and other retroviruses. Science 341:903-906.

89. Lahaye X, Satoh T, Gentili M, Cerboni S, Conrad C, Hurbain I, EI Marjou A, Lacabaratz C, Lelievre JD, Manel N. 2013. The capsids of HIV-1 and HIV-2 determine immune detection of the viral cDNA by the innate sensor cGAS in dendritic cells. Immunity 39:1132-1142.

90. Chesnoy S, Huang L. 2000. Structure and function of lipid-DNA complexes for gene delivery. Annu Rev Biophys Biomol Struct 29:27-47.

91. Stebelska K, Dubielecka PM, Sikorski AF. 2005. The effect of PS content on the ability of natural membranes to fuse with positively charged liposomes and lipoplexes. J Membr Biol 206:203-214.

92. Wattiaux R, Jadot M, Warnier-Pirotte MT, Wattiaux-De Coninck S. 1997. Cationic lipids destabilize lysosomal membrane in vitro. FEBS Lett 417:199-202.

93. DiGiuseppe S, Bienkowska-Haba M, Hilbig L, Sapp M. 2014. The nuclear retention signal of HPV16 L2 protein is essential for incoming viral genome to transverse the trans-Golgi network. Virology 458-459:93-105. 
94. Medzhitov R. 2007. Recognition of microorganisms and activation of the immune response. Nature 449:819-826.

95. Ma Z, Ni G, Damania B. 2018. Innate Sensing of DNA Virus Genomes. Annu Rev Virol 5:341362.

96. Tummers B, Goedemans R, Pelascini LP, Jordanova ES, van Esch EM, Meyers C, Melief CJ, Boer JM, van der Burg SH. 2015. The interferon-related developmental regulator 1 is used by human papillomavirus to suppress NFkappaB activation. Nat Commun 6:6537.

97. Albertini S, Lo Cigno I, Calati F, De Andrea M, Borgogna C, Dell'Oste V, Landolfo S, Gariglio M. 2018. HPV18 Persistence Impairs Basal and DNA Ligand-Mediated IFN-beta and IFN-lambda1 Production through Transcriptional Repression of Multiple Downstream Effectors of Pattern Recognition Receptor Signaling. J Immunol 200:2076-2089.

98. Stanley MA. 2012. Epithelial cell responses to infection with human papillomavirus. Clin Microbiol Rev 25:215-222.

99. Bienkowska-Haba M, Luszczek W, Keiffer TR, Guion LGM, DiGiuseppe S, Scott RS, Sapp M. 2017. Incoming human papillomavirus 16 genome is lost in PML protein-deficient HaCaT keratinocytes. Cell Microbiol 19.

100. Luff JA, Yuan H, Kennedy D, Schlegel R, Felsburg P, Moore PF. 2014. Keratinocyte antiviral response to Poly $(\mathrm{dA}: \mathrm{dT})$ stimulation and papillomavirus infection in a canine model of X-linked severe combined immunodeficiency. PLoS One 9:e102033.

101. Grandvaux N, Servant MJ, tenOever B, Sen GC, Balachandran S, Barber GN, Lin R, Hiscott J. 2002. Transcriptional profiling of interferon regulatory factor 3 target genes: direct involvement in the regulation of interferon-stimulated genes. J Virol 76:5532-5539.

102. Helbig KJ, Ruszkiewicz A, Lanford RE, Berzsenyi MD, Harley HA, McColl SR, Beard MR. 2009. Differential expression of the CXCR3 ligands in chronic hepatitis $C$ virus (HCV) infection and their modulation by HCV in vitro. J Virol 83:836-846.

103. Brownell J, Bruckner J, Wagoner J, Thomas E, Loo YM, Gale M, Jr., Liang TJ, Polyak SJ. 2014. Direct, interferon-independent activation of the CXCL10 promoter by NF-kappaB and interferon regulatory factor 3 during hepatitis $C$ virus infection. J Virol 88:1582-1590.

104. Durfee LA, Lyon N, Seo K, Huibregtse JM. 2010. The ISG15 conjugation system broadly targets newly synthesized proteins: implications for the antiviral function of ISG15. Mol Cell 38:722-732.

105. Dufour JH, Dziejman M, Liu MT, Leung JH, Lane TE, Luster AD. 2002. IFN-gammainducible protein 10 (IP-10; CXCL10)-deficient mice reveal a role for IP-10 in effector T cell generation and trafficking. J Immunol 168:3195-3204.

106. Clark-Lewis I, Mattioli I, Gong JH, Loetscher P. 2003. Structure-function relationship between the human chemokine receptor CXCR3 and its ligands. J Biol Chem 278:289-295.

107. Wang W, Uberoi A, Spurgeon M, Gronski E, Majerciak V, Lobanov A, Hayes M, Loke A, Zheng ZM, Lambert PF. 2020. Stress keratin 17 enhances papillomavirus infection-induced disease by downregulating T cell recruitment. PLoS Pathog 16:e1008206.

108. Lo Cigno I, De Andrea M, Borgogna C, Albertini S, Landini MM, Peretti A, Johnson KE, Chandran B, Landolfo S, Gariglio M. 2015. The Nuclear DNA Sensor IFI16 Acts as a Restriction Factor for Human Papillomavirus Replication through Epigenetic Modifications of the Viral Promoters. J Virol 89:7506-7520.

109. Riva G, Biolatti M, Pecorari G, Dell'Oste V, Landolfo S. 2019. PYHIN Proteins and HPV: Role in the Pathogenesis of Head and Neck Squamous Cell Carcinoma. Microorganisms 8.

110. Park JS, Kim EJ, Kwon HJ, Hwang ES, Namkoong SE, Um SJ. 2000. Inactivation of interferon regulatory factor-1 tumor suppressor protein by HPV E7 oncoprotein. Implication for the E7-mediated immune evasion mechanism in cervical carcinogenesis. J Biol Chem 275:6764-6769.

111. Perea SE, Massimi P, Banks L. 2000. Human papillomavirus type 16 E7 impairs the activation of the interferon regulatory factor-1. Int $\mathrm{J}$ Mol Med 5:661-666. 
19 112. Lee HS, Lee JH, Park YM. 2017. E7 protein of cutaneous human papillomavirus attenuates viperin expression in human keratinocytes. J Dermatol Sci 87:91-94.

113. Wang H, Mo P, Ren S, Yan C. 2010. Activating transcription factor 3 activates p53 by preventing E6-associated protein from binding to E6. J Biol Chem 285:13201-13210.

114. Guan KL, Jenkins CW, Li Y, Nichols MA, Wu X, O'Keefe CL, Matera AG, Xiong Y. 1994. Growth suppression by p18, a p16INK4/MTS1- and p14INK4B/MTS2-related CDK6 inhibitor, correlates with wild-type pRb function. Genes Dev 8:2939-2952.

115. Wang X, Meyers C, Guo M, Zheng ZM. 2011. Upregulation of p18Ink4c expression by oncogenic HPV E6 via p53-miR-34a pathway. Int J Cancer 129:1362-1372.

116. Wang S, EI-Deiry WS. 2003. TRAIL and apoptosis induction by TNF-family death receptors. Oncogene 22:8628-8633.

117. Kabsch K, Alonso A. 2002. The human papillomavirus type 16 E5 protein impairs TRAIL- and FasL-mediated apoptosis in HaCaT cells by different mechanisms. J Virol 76:12162-12172.

118. Kabsch K, Mossadegh N, Kohl A, Komposch G, Schenkel J, Alonso A, Tomakidi P. 2004. The HPV-16 E5 protein inhibits TRAIL- and FasL-mediated apoptosis in human keratinocyte raft cultures. Intervirology 47:48-56.

119. Mackenzie KJ, Carroll P, Martin CA, Murina O, Fluteau A, Simpson DJ, Olova N, Sutcliffe H, Rainger JK, Leitch A, Osborn RT, Wheeler AP, Nowotny M, Gilbert N, Chandra T, Reijns MAM, Jackson AP. 2017. cGAS surveillance of micronuclei links genome instability to innate immunity. Nature 548:461-465.

120. Zierhut C, Yamaguchi N, Paredes M, Luo JD, Carroll T, Funabiki H. 2019. The Cytoplasmic DNA Sensor cGAS Promotes Mitotic Cell Death. Cell 178:302-315 e323.

121. Burleigh K, Maltbaek JH, Cambier S, Green R, Gale M, Jr., James RC, Stetson DB. 2020. Human DNA-PK activates a STING-independent DNA sensing pathway. Sci Immunol $\mathbf{5}$.

122. Pennington MR, Saha A, Painter DF, Gavazzi C, Ismail AM, Zhou X, Chodosh J, Rajaiya J. 2019. Disparate Entry of Adenoviruses Dictates Differential Innate Immune Responses on the Ocular Surface. Microorganisms 7.

123. Teigler JE, Kagan JC, Barouch DH. 2014. Late endosomal trafficking of alternative serotype adenovirus vaccine vectors augments antiviral innate immunity. J Virol 88:10354-10363.

124. Lee JS, Ismail AM, Lee JY, Zhou X, Materne EC, Chodosh J, Rajaiya J. 2019. Impact of dynamin 2 on adenovirus nuclear entry. Virology 529:43-56.

125. Stuart JD, Holm GH, Boehme KW. 2018. Differential Delivery of Genomic Double-Stranded RNA Causes Reovirus Strain-Specific Differences in Interferon Regulatory Factor 3 Activation. J Virol 92.

126. Dharan A, Opp S, Abdel-Rahim O, Keceli SK, Imam S, Diaz-Griffero F, Campbell EM. 2017. Bicaudal D2 facilitates the cytoplasmic trafficking and nuclear import of HIV-1 genomes during infection. Proc Natl Acad Sci U S A 114:E10707-E10716.

127. O'Brien M, Manches O, Wilen C, Gopal R, Huq R, Wu V, Sunseri N, Bhardwaj N. 2016. CD4 Receptor is a Key Determinant of Divergent HIV-1 Sensing by Plasmacytoid Dendritic Cells. PLoS Pathog 12:e1005553.

128. Oguin TH, 3rd, Sharma S, Stuart AD, Duan S, Scott SA, Jones CK, Daniels JS, Lindsley CW, Thomas PG, Brown HA. 2014. Phospholipase D facilitates efficient entry of influenza virus, allowing escape from innate immune inhibition. J Biol Chem 289:25405-25417.

129. Nonnenmacher ME, Cintrat JC, Gillet D, Weber T. 2015. Syntaxin 5-dependent retrograde transport to the trans-Golgi network is required for adeno-associated virus transduction. J Virol 89:1673-1687.

130. Chen YJ, Liu X, Tsai B. 2019. SV40 Hijacks Cellular Transport, Membrane Penetration, and Disassembly Machineries to Promote Infection. Viruses 11.

131. Mbianda C, El-Meanawy A, Sorokin A. 2015. Mechanisms of BK virus infection of renal cells and therapeutic implications. J Clin Virol 71:59-62. 
132. Schelhaas M, Malmstrom J, Pelkmans L, Haugstetter J, Ellgaard L, Grunewald K, Helenius A. 2007. Simian Virus 40 depends on ER protein folding and quality control factors for entry into host cells. Cell 131:516-529.

133. Bennett SM, Jiang M, Imperiale MJ. 2013. Role of cell-type-specific endoplasmic reticulumassociated degradation in polyomavirus trafficking. J Virol 87:8843-8852.

134. Caller LG, Davies CTR, Antrobus R, Lehner PJ, Weekes MP, Crump CM. 2019. Temporal Proteomic Analysis of BK Polyomavirus Infection Reveals Virus-Induced G2 Arrest and Highly Effective Evasion of Innate Immune Sensing. J Virol 93.

135. Van Doorslaer K, Chen D, Chapman S, Khan J, McBride AA. 2017. Persistence of an Oncogenic Papillomavirus Genome Requires cis Elements from the Viral Transcriptional Enhancer. mBio 8.

136. Van Doorslaer K, Porter S, McKinney C, Stepp WH, McBride AA. 2016. Novel recombinant papillomavirus genomes expressing selectable genes. Sci Rep 6:37782.

137. Chapman S, McDermott DH, Shen K, Jang MK, McBride AA. 2014. The effect of Rho kinase inhibition on long-term keratinocyte proliferation is rapid and conditional. Stem Cell Res Ther 5:60.

138. Campos SK, Ozbun MA. 2009. Two highly conserved cysteine residues in HPV16 L2 form an intramolecular disulfide bond and are critical for infectivity in human keratinocytes. PLoS One 4:e4463.

139. Pyeon D, Lambert PF, Ahlquist P. 2005. Production of infectious human papillomavirus independently of viral replication and epithelial cell differentiation. Proc Natl Acad Sci U S A 102:9311-9316.

140. Kim D, Langmead B, Salzberg SL. 2015. HISAT: a fast spliced aligner with low memory requirements. Nat Methods 12:357-360.

141. Liao Y, Smyth GK, Shi W. 2014. featureCounts: an efficient general purpose program for assigning sequence reads to genomic features. Bioinformatics 30:923-930.

142. Love MI, Huber W, Anders S. 2014. Moderated estimation of fold change and dispersion for RNA-seq data with DESeq2. Genome Biol 15:550.

143. R Core Team. 2018. R: A language and environment for statistical computing, on $R$ Foundation for Statistical Computing, Vienna, Austria. https://www.R-project.org/.

144. R Team. 2016. RStudio: Integrated Development for R, on RStudio, Inc., Boston, MA. http://www.rstudio.com/.

145. Raudvere U, Kolberg L, Kuzmin I, Arak T, Adler P, Peterson H, Vilo J. 2019. g:Profiler: a web server for functional enrichment analysis and conversions of gene lists (2019 update). Nucleic Acids Res 47:W191-W198.

146. Kolde R. 2019. pheatmap: Pretty Heatmaps. R package version 1.0.12. https://CRAN.Rproject.org/package=pheatmap

147. Blighe K. 2019. EnhancedVolcano: Publication-ready volcano plots with enhanced colouring and labeling. $\mathrm{R}$ package version 1.0.1. https://github.com/kevinblighe/EnhancedVolcano 


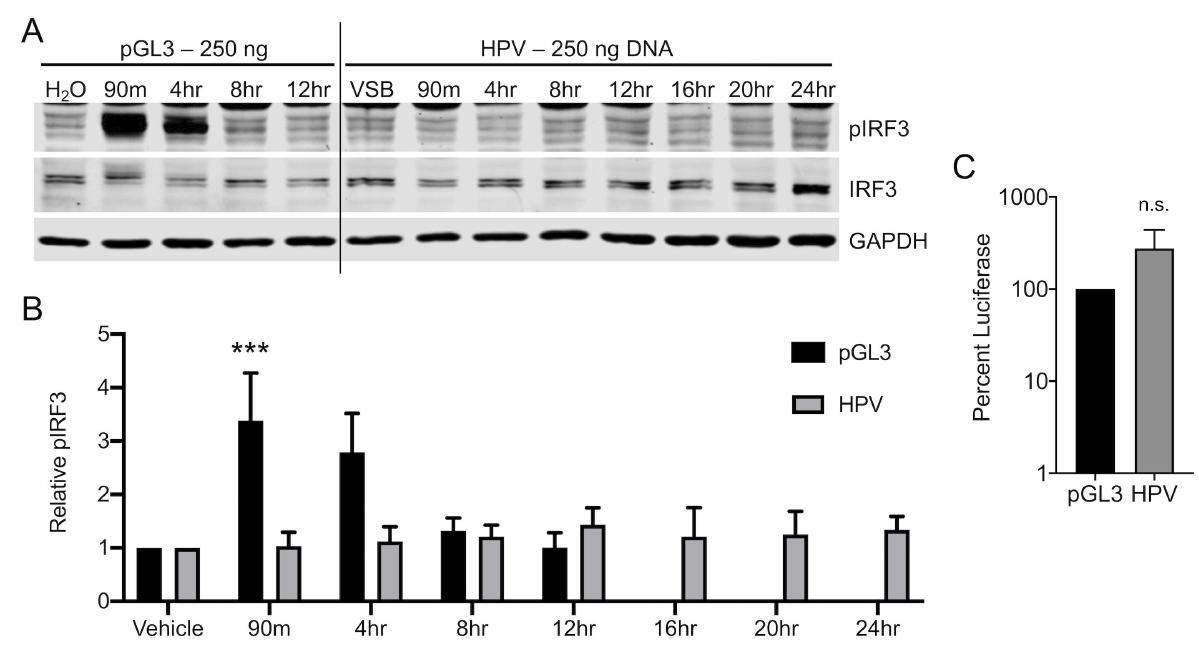


A

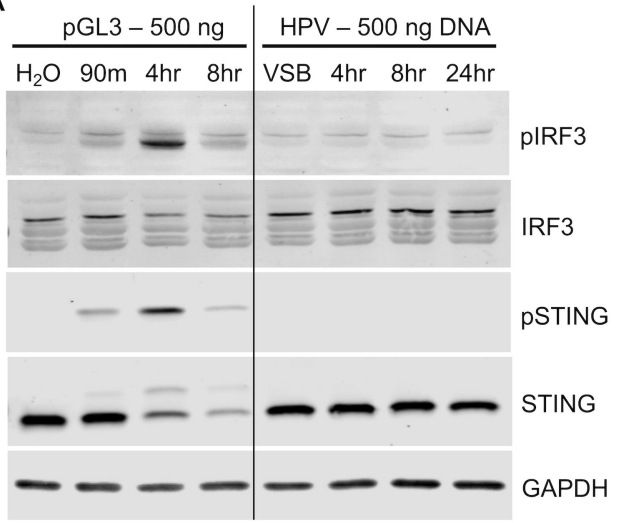

B

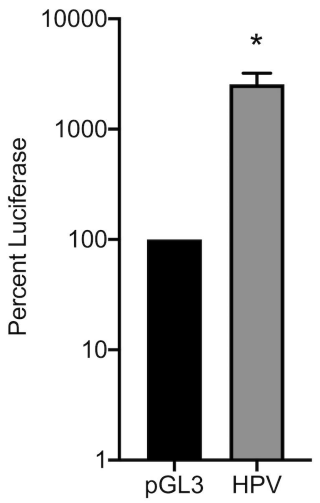




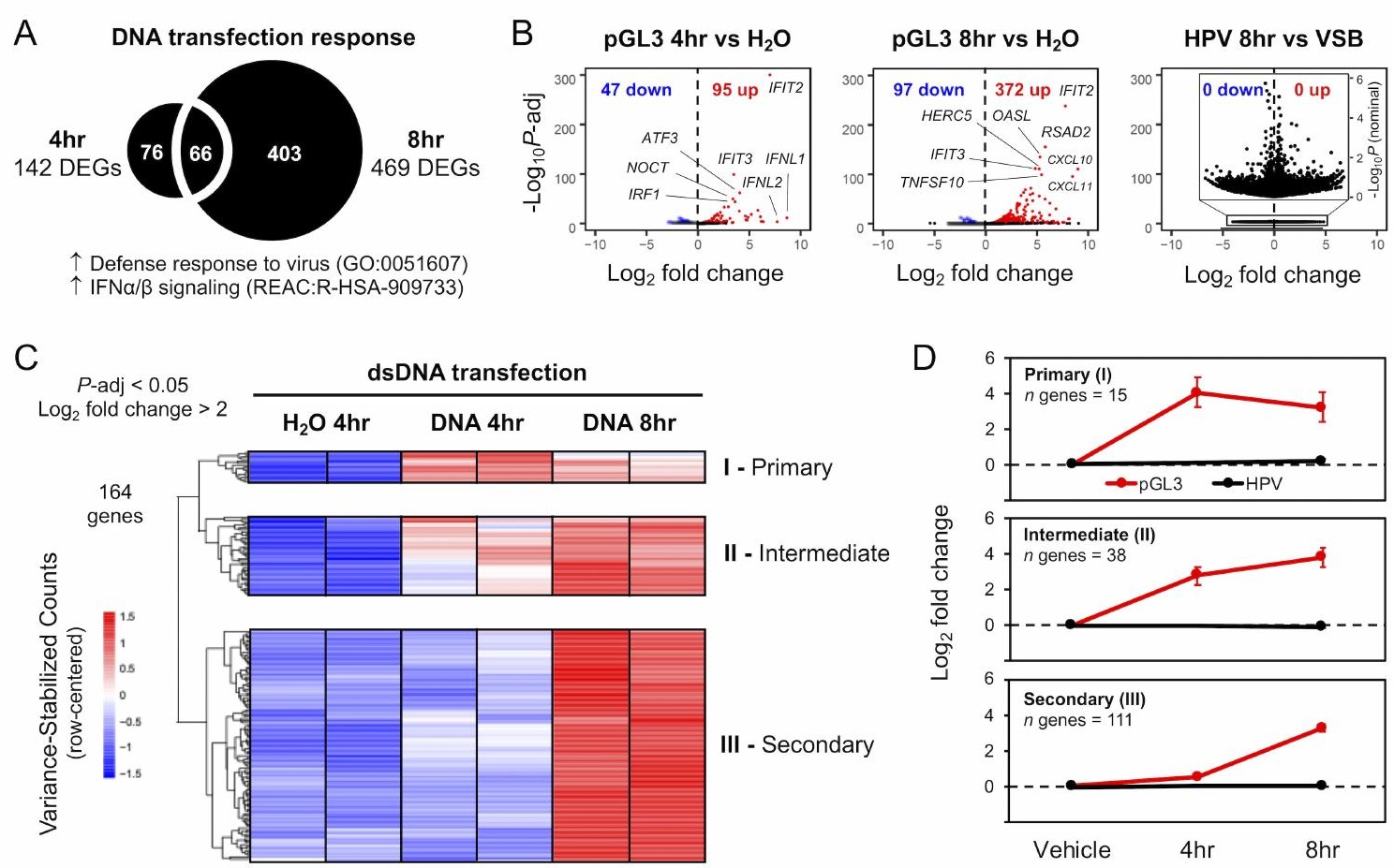


